\title{
Further Analyses of the Orthopoxviruses Volepox Virus and Raccoon Poxvirus
}

\author{
JANICE C. KNIGHT, ${ }^{*}$ CYNTHIA S. GOLDSMITH, ${ }^{*}$ AZAIBI TAMIN, ${ }^{*}$ RUSSELL L. REGNERY, ${ }^{*}$ \\ DAVID C. RFGNFRY AND JOSEPH J. ESPOSITO*,1
} *Division of Viral and Rickettsial Diseases, National Center for Infectious Diseases, Centers for Disease Control, Atlanta, Georgia $30333 ;$ and
+Department of Biological Sciences, Stanford University, Stanford, California 94305

Received March 16, 1992; accepted May 20, 1992

\begin{abstract}
Volepox virus (VPX) from skin lesions on a vole and a piñon mouse caught in California and raccoon poxvirus (RCN) from raccoons trapped in Maryland were examined to begin elucidating their relationship to other orthopoxviruses, most of which are not known to be indigenous to the Americas. VPX and RCN produced pinpoint, nonhemorrhagic pocks on chick embryo chorioallantoic membranes. In cell cultures both viruses produced 1-mm diameter, irregular plaques, A-type inclusions (ATIs), and despite production of hemagglutinin, both viruses caused syncytia formation. Considerable cross-hybridization was seen between VPX and RCN DNA and the DNAs of other orthopoxviruses; however, Hindlll cleavage site maps showed marked central and terminal region differences between VPX (222.8 kbp) and RCN (224.8 kbp) DNA and mapped DNAs of other orthopoxviruses. Cognate DNAs of the ATI 160-kDa protein and 38-kDa serine protease inhibitor homologue of cowpox virus (CPV) and the 14-kDa fusion protein of vaccinia virus (VAC) were present within the right end of VPX and RCN DNA, matching their location in CPV and VAC. VPX and RCN, respectively, expressed a 150- and a 155-kDa ATI major protein and a 20- and an 18-kDa fusion protein. Low stringency annealing suggested that cognate DNAs for the VAC growth factor and the $\alpha$-amanitin target protein were present within the left end of VPX and RCN DNA, matching their location in VAC. Terminal tandem repeat sequences of VAC and RCN did not cross-hybridize with each other or with VPX DNA end fragments. Together, the data suggested that VPX and RCN are phylogenetically rather distant from orthopoxviruses not indigenous to the Americas, although genetic information is arranged as in other examined orthopoxviruses. (c) 1992 Academic Press, Inc.
\end{abstract}

\section{INTRODUCTION}

In this report, selected traits of volepox virus (VPX) and raccoon poxvirus (RCN) are compared to examine their relationship to other orthopoxviruses, most of which are not known to occur naturally in the Americas. Volepox virus was first isolated from a skin lesion on a vole (Microtus californicus) caught in 1985 in Portola Valley, San Mateo County, CA (Regnery, 1987). A serosurvey of voles from the San Francisco Bay area suggested that VPX was enzootic in voles, and positive sera showed greater reactivity with a VPX hemagglutinin (HA) preparation than with $\mathrm{RCN}$ or vaccinia virus (VAC) HA preparations. Footpad or tail inoculation of seronegative voles produced a localized lesion and induced hemagglutination-inhibiting (HAI) antibodies. A second isolate, from a scab on a piñon mouse (Peromyscus truel) caught in 1988 on the Jasper Ridge Biological Preserve, San Mateo County, CA, seemed identical to the first VPX isolate by various DNA and biologic assays.

Raccoon poxvirus was isolated from upper respiratory tissues of 2 of 92 outwardly healthy raccoons (Procyon lotor) trapped in 1961 near Aberdeen, MD (Her-

\footnotetext{
1 To whom reprint requests should be addressed.
}

man, 1964). Alexander et al. (1972) later reported that sera of 22 of the animals had RCN HAl antibodies, but the sera partly cross-reacted with a VAC HA preparation and did not cross-react with a monkeypox virus (MPV) HA. Thomas et al. (1975) described several features of RCN-infected cells, including the formation of syncytia in monkey kidney cell cultures and the HAl partial cross-reactivity with homogenates of cells infected with VAC or cowpox virus (CPV). Patel et al. (1986) reported that cells infected with RCN produce cytoplasmic A-type inclusions (ATIS) that contain a $155-\mathrm{kDa}$ major protein that is serologically related to the CPV $160-k D a$ ATI protein. To date, three versions of the Hindlll map of fragments $>2 \mathrm{kbp}$ have been reported for the isolate RCN CDC/V71-1-85A (Esposito and Knight, 1985; Parsons and Pickup, 1987; Fenner et al., 1989). Recently, DNA restriction enzyme digest comparisons of RCN CDC/N71-I-85A and the second isolate, RCN CDCN71-I-85B, showed different terminal region patterns, suggesting that polymorphisms have developed from passaging the original isolates differently since 1961 (unpublished data). The sequences of the terminal Sall restriction fragment of RCN CDCN7 1-I-85A have been determined (Parsons and Pickup, 1987) and shown to contain a tandem repeat sequence (TRS) region composed of six subtypes 
of TRS. Although RCN TRSs were distinct from VAC and CPV TRSs, the investigators deduced a consensus sequence, demonstrating that orthopoxviruses have similar repeated and nonrepeated DNA end sequences arrayed in a similar manner. Parsons and Pickup (1990) also showed that RCN and CPV transcribe RNAs corresponding to their hairpin-end DNAs.

Although the DNAs of all orthopoxviruses cross-hybridize extensively, in the present report, HindIII DNA maps of VPX and RCN indicated that these viruses are diverged from each other. VPX and RCN DNAs were rather diverged from all other examined orthopoxviruses whose DNAs appear much more related (Esposito and Knight, 1985; Mackett and Archard, 1979). Insight into the extent of the sequence differences was gained by examining VPX and RCN for selected components. Accordingly, we show by DNA and antigenic analyses that VPX and RCN contain counterparts of the CPV 160-kDa ATI protein (Patel et al., 1986; Funahashi et al., 1988) and the VAC 14-kDa fusion protein (Gong et al., 1990). We also show that VPX and RCN contain cognate DNAs of the CPV 38-kDa homologue of serine protease inhibitor (serpin) molecules (Pickup et al., 1986), the VAC growth factor (VGF) (Venkatesan et al., 1982), and the VAC $\alpha$-amanitin resistance protein (Tamin et al., 1988).

\section{MATERIALS AND METHODS}

\section{Viruses}

VPX from Peromyscus truei was isolated on the CAM of 12-day-old chick embryos, and a single pock al $72 \mathrm{hr}$ p.i. at $35^{\circ}$ was excised and passaged into VERO monkey kidney cells. RCN isolate CDC/V71-I-85A that had been plaque-purified from trypsinized ATls (Parsons and Pickup, 1987), Brighton CPV, and VAC strains Wyeth New York Board of Health (NYBH) and Lister were grown in human $143 \mathrm{~B}$ or VERO cells. Thinsection electron microscopy was done as described by Knight et al. (1989).

\section{DNA analyses}

DNA was prepared from purified virions or lysates of infected cells as described previously (Esposito et al., 1981b, 1988; Knight et al., 1989). Clamped homogeneous electric field (CHEF) separation of viral DNAs was done in $1.25 \%$ agarose gels in $45 \mathrm{mM}$ Tris base, $45 \mathrm{mM}$ boric acid, $10 \mathrm{mM} \mathrm{Na}$,EDTA buffer at 200 constant volts and $15^{\circ}$ for $50 \mathrm{hr}$ with no ramping (initial and final A was $20 \mathrm{sec}$ ), using a Bio-Rad, Inc., CHEF-DRII apparatus (Chu et al., 1986; Vollrath and Davis, 1987).

The Hindll! map of RCN DNA was updated by crosshybridization overlap analyses with cloned DNA frag- ments of WR VAC and CPV that are described under Results (Table 2) and with MPV-mapped and cloned DNA fragments (Esposito et al., 1981a; Esposito and Knight, 1985). The VPX map was resolved similarly except that hybridizations included cloned RCN Hindll! DNA fragments described in the Results (Table 2). Fragment snap-back analysis and hybridizations were done as described by Esposito and Knight (1985). Standard $\left(65^{\circ}\right)$ and reduced $\left(42^{\circ}\right)$ stringency hybridizations were done in $0.5 \mathrm{M} \mathrm{NaCl}, 0.1 \mathrm{M} \mathrm{NaH}_{2} \mathrm{PO}_{4}, 0.1 \mathrm{M}$ Tris base, $0.1 \%$ SDS, $2 \mathrm{mM} \mathrm{Na} \mathrm{EDDTA}_{2}$ buffer, followed by washing DNA blots at room temperature in $0.1 \%$ SDS, $2 \mathrm{mM} \mathrm{Na}_{2}$ EDTA, $10 \mathrm{mM}$ Na-phosphate, $\mathrm{pH} 7$. buffer.

The following plasmids that contain DNA fragments of VAC strain WR were used: a pBR322 series containing fragments Hindlll-D through -O (kindly supplied by D. Pickup); a pUC13 series with individual HindIII-Sall, Sall, and ECORI segments that span the entirety of DNA fragments HindIII-B and $-C$ up to base 120 of the respective terminal apexes (kindly supplied by M. Merchlinsky; Merchlinsky and Moss, 1988); pAG-5 containing a 3.5-kbp Sall-EcoRI terminal fragment (kindly supplied by B. Moss; Baroudy and Moss, 1982); and pDel 13 containing a 1.5-kbp EcoRI segment with DNA for the $14-\mathrm{kDa}$ fusion protein and a small portion of the VAC ATI analogue protein (kindly supplied by M. Esteban; Dallo et al., 1987). We also used pGP1247.2 that contains a 688-bp Pst portion of the CPV 38-kDa serpin DNA (kindly supplied by G. Palumbo; Palumbo et al., 1989); p2031 that has a 2-kbp Accl segment of the CPV $160-k D a$ ATI gene (kindly supplied by D. Pickup; Patel and Pickup, 1987); and p1067 that contains the 2.2-kbp Sall TRS segment of RCN HindIII-O (kindly supplied by D. Pickup; Parsons and Pickup, 1987). Polymerase chain reactions (PCR) were done as described by Sambrook et al. (1989) with intact VAC NYBH DNA and primers based on sequences reported for the WR VAC VGF (Venkatesan et al., 1982) and for the openreading-frame (ORF) WR VAC N2L (Tamin et al., 1988). Amplified segments included VGF DNA from base +1 to +483 (start codon through the stop codon at +420 to the transcript terminator) and N2L DNA base +92 to +379 .

\section{Western blot assays}

Monoclonal antibody (MAb-C3, kindly supplied by M. Esteban; Rodriguez et al., 1985, 1987) that recognizes the WR VAC 14-kDa protein involved in $\mathrm{pH} 5$-inducible cell fusion and antigen-purified rabbit antiserum (kindly supplied by D. Pickup; Patel et al., 1986) that recognizes the CPV ATI $160-\mathrm{kDa}$ protein were used to detect analogue proteins of RCN and VPX. 
Western blots (Towbin and Gordon, 1984; Burnette, 1981; Towbin et al., 1979) used buffered $5 \%$ nonfat dry milk "BLOTTO" solution (Johnson et al., 1984) for blocking and immunologic reactions and [ $\left.{ }^{125} \mid\right]$ ProteinA for detecting antibody reactivity. SDS-PAGE (Laemmli, 1970) was done with 10-20\% gradient gels to resolve ATI protein analogues and $12 \%$ gels to resolve fusion protein analogues (sample buffer was adjusted to $100 \mathrm{mM}$ dithiothreitol (Rodriguez et al., 1987)).

\section{RESULTS}

\section{Morphologic features of VPX and RCN in culture}

As shown in Figs. $1 A$ and $1 B, V P X$ and RCN pocks at $72 \mathrm{hr}$ p.i. were small (1-mm diameter), white (nonhemorrhagic), irregular-shaped, and slightly raised with a flat surface; occasional tiny pocks and punctate pocks were seen which have not been described for other orthopoxviruses (e.g., variola, camelpox, and ectromelia viruses) that produce pinpoint pocks. Both isolates of RCN and VPX from M. californicus and P. truei produced identical pocks, and examination of hematoxylin-eosin-stained sections of infected CAMs suggested that the punctate pocks were mature, ulcerated forms and that the tiny pocks may be immature or possibly secondary pock forms (data not shown).

As shown in Figs. $1 \mathrm{C}$ and 1D, phase contrast microscopy of the periphery of a viral plaque in VERO cell monolayers infected with VPX or RCN revealed that both viruses induced cell fusion which results in the formation of large syncytia containing many clearly delineated nuclei. Both viruses produced irregularshaped, 1-mm diameter plaques in VERO cell monolayers.

Examination of virosomes by electron microscopy of thin-sectioned, infected VERO cells (Fig. 2) revealed that $\mathrm{VPX}$ and RCN morphogenesis stages were very similar to those of other orthopoxviruses. Figure $2 A$ shows VPX immature virus particles (open arrows) appearing to form via condensation of electron-dense nuclcic acid in close association with viral nascent outer membranes. Both viruses (Figs. 2A, 2B, and 2D) produced classic, CPV-like, spherical, polyribosomeringed ATIs-dense protein matrices that include immature and mature virus particles. However, RCN-infected cells also showed rather pleomorphic ATIs that were collapsed in appearance and laden with mature virions (Fig. 2D, arrow). Double-enveloped virions were seen in Golgi complexes of cells infected with VPX (Fig. 2C, solid arrows) or RCN (Fig. 2D, arrowheads). As depicted in Fig. 2C (arrowheads) with VPX, in extracellular spaces RCN and VPX showed virions with a single lipid bilayer envelope around the viral outer membrane, reminiscent of extracellular enveloped virions.

\section{DNA sizes}

Pulsed-field electrophoresis (Fig. 3) of intact virion DNAs indicated that VPX, RCN, CPV, and VAC DNA sizes agreed with DNA sizes estimated by summing the sizes of HindllI DNA fragments resolved in standard agarose gels. Sizes of VPX HindlII DNA fragments are listed in Table 1. For conciseness in the text, HindlII fragment sizes for RCN, CPV, or VAC DNAs are not listed since they essentially have been described by Esposito and Knight (1985) and Parsons and Pickup (1987); however, HindlII DNA patterns are shown below in Fig. 5A for VPX (24 fragments, $222.8 \mathrm{kbp}$ ), RCN (29 fragments, $224.8 \mathrm{kbp}$ ), Brighton CPV (20 fragments, $222.0 \mathrm{kbp}$ ), and NYBH VAC (16 fragments, $197.9 \mathrm{kbp})$.

\section{Updating the RCN HindllI map}

As mentioned above, development of the Hindill map of RCN DNA has been ongoing, mainly because of the HindIII DNA pattern complexity. We decided to update earlier versions of the map when we noted that insertion of a rabies virus CDNA into the RCN HindIII-E (TK locus) gave a recombinant virus DNA with a 2-molar HindllI-E fragment (Esposito et al., 1988), indicating that RCN DNA contained a 3-molar HindIII-E fragment, not a 2-molar one as suggested in the earlier maps. Moreover, during production of a RCN HindllI DNA library, we recovered three plasmids with different Hindlll-E inserts that gave six different restriction profiles (three inserts in two orientations) and three different profiles by Southern blot hybridizations with BamHI-digested RCN DNA (data not shown). The map positions of RCN Hindll- $E$, - $E^{\prime}$, and - $E^{\prime \prime}$ were then confirmed by hybridizations with mapped DNAs of other orthopoxviruses. Other cross-hybridizations (Table 2A and data not shown) revealed the positions of small DNA fragments not shown in prior versions of the RCN Hindll map. All currently detected fragments are now accounted for in the revised RCN HindIII DNA map shown in Fig. 4.

\section{VPX HindIII map}

The VPX Hind III map shown in Fig. 4 was determined by resolving VPX DNA cross-hybridization overlaps versus cloned RCN DNA Hindlll fragments and DNA fragments of other orthopoxviruses that are described 

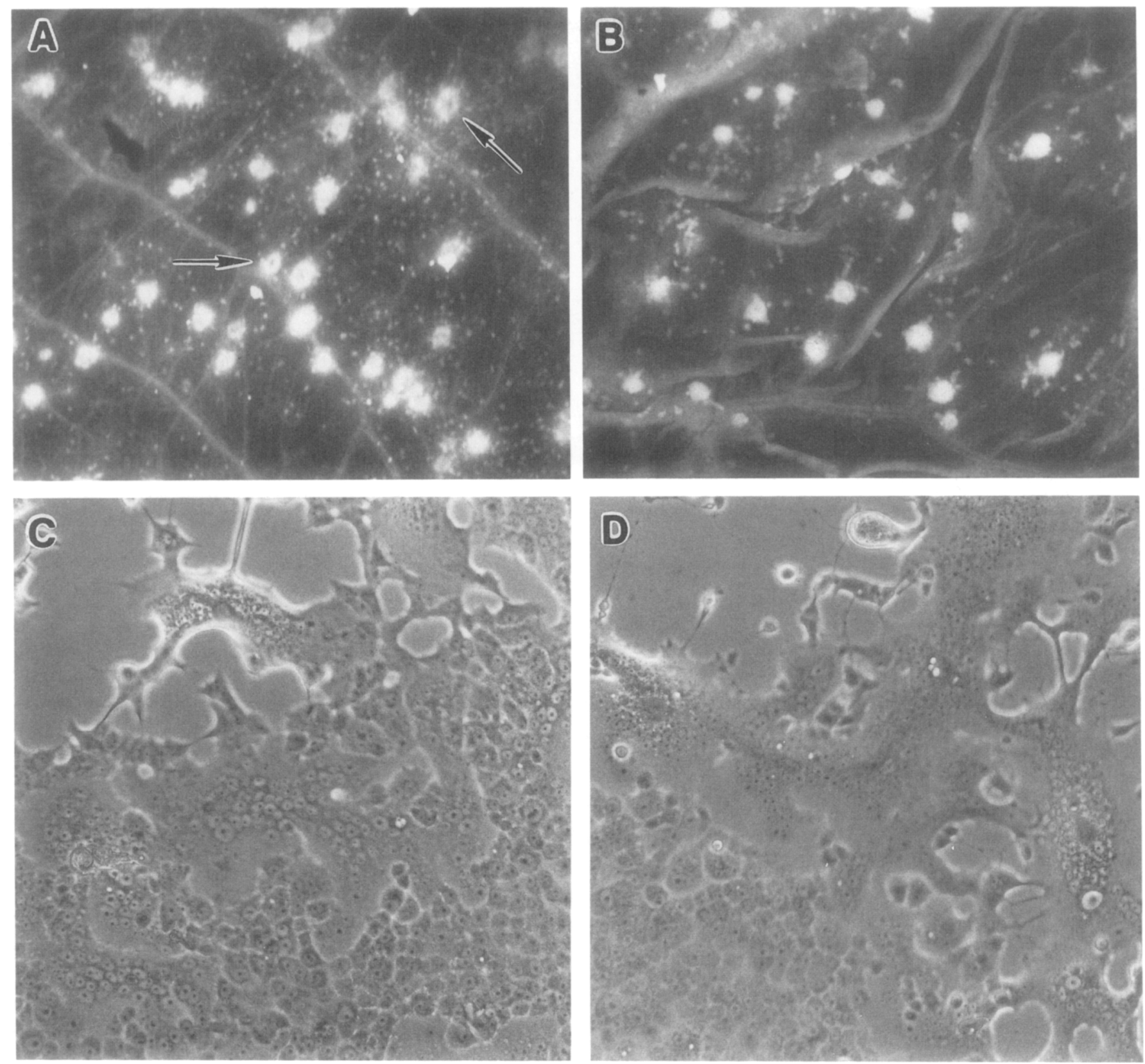

FIG. 1. VPX (A) and RCN (B) pock morphology on the CAM of 12-day-old chicken embryos at $72 \mathrm{hr}$ p.i. and the cytopathic effect produced by these viruses in VERO cells. VPX and RCN showed virtually identical pinpoint, nonhemorrhagic pocks; however, a few mature pocks with punctate centers (A, arrows) can also be seen, and many tiny $(<0.5 \mathrm{~mm})$ pocks are apparent. Extensive fusion of cells into large syncytia were characteristic of the cytopathic effect of VPX (C) and RCN (D).

in Table 2. When we compared the RCN and VPX maps with reported Hindlll maps of CPV, VAC (included in Fig. 4) and other orthopoxviruses (Esposito and Knight, 1985; Mackett and Archard, 1979), we noted, despite extensive cross-hybridization, that RCN and VPX DNA sequences were diverged from each other and that these DNAs were quite diverged, throughout the central and terminal regions, from the DNAs of CPV, VAC, and other orthopoxviruses.

\section{Extent of DNA divergence}

RCN, VPX, CPV, and VAC DNA fragments cross-hybridize extensively under our stringency conditions which require $>85 \%$ sequence homology, thus the total genetic information in these four viruses is highly similar. However, the conservation of cleavage sites, especially Hindlll sites, among the DNAs of orthopoxviruses can be used to judge the degree to which there 

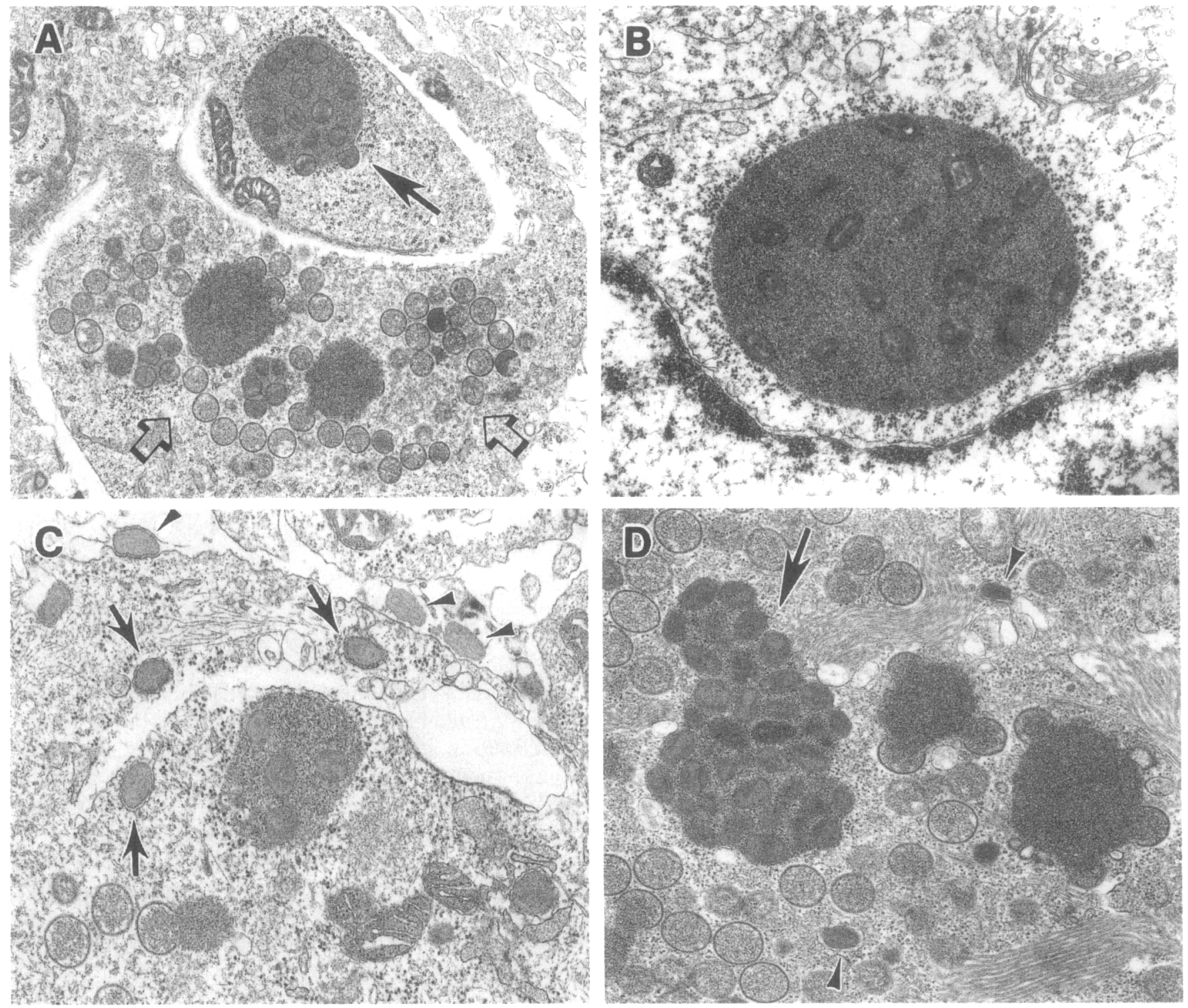

FIG. 2. VPX and RCN in VERO cell thin sections. As depicted in A for VPX, both viruses showed virosomes (open arrows) with virion morphogenesis appearing to proceed by coalescence of electron-dense DNA with nascent membranes to form immature particles. Cells infected with either virus contained cytuplasmic, spherical, polyribosome-ringed A-type inclusions, as exampled for VPX in A (solid arrow) and at higher magnification for RCN in B. As depicted with VPX in C, both viruses showed a double-lipid layer envelope (solid arrows) around virus particles in Golgi complexes and a single lipid layer (arrowheads) envelope around virus particles in extracellular spaces. In D, a pleomorphic virus-laden inclusion (arrow) in a RCN virosome is shown next to maturing virus particles and a double-layer enveloped virion (arrowhead).

are very highly conserved sequence domains. Accordingly, we noted that 5 of 10 comigrating Hindlll fragments of VPX and RCN DNA (Fig. 5A) cross-hybridized (Table 2A) thus occupy corresponding domains in their genome (VPX HindIII-E', -I, -O, - R, and -U, respectively, comigrated and annealed with RCN HindIII-E', $-I,-O^{\prime}$, $-Q$, and $-U)$. We estimated from the maps shown in Fig. 4 that these corresponding domains account for about $30 \mathrm{kbp}$, or $15 \%$ of the central region of $\mathrm{VPX}$ and RCN DNA. When CPV and VAC DNAs were compared with each other, about $80 \mathrm{kbp}$, or $40 \%$, of their DNA central region restriction sites were conserved (CPV Hindl|I-G, $-F,-Q,-M,-J,-N,-K$, and $-E$, respectively, comigrate and cross-hybridize with VAC HindlII-E, $-F,-O,-I,-G$, $-L$, $-H$, and $-D$ ). About $16 \mathrm{kbp}$ (Hindlll-E' and $-U$ ), or $7 \%$, of the VPX genome represented a domain of central DNA that was very highly conserved among the four DNAs shown in Fig. 4. About $30 \mathrm{kbp}$, or $15 \%$ of RCN DNA represented a domain among $R C N, C P V$, and VAC that contained highly conserved sequences (RCN Hindlll$E^{\prime \prime},-E^{\prime}$, and $-U$, respectively, annealed with CPV HindllI$G,-F$, and $-Q$ and with VAC Hindlli-F, $-E$, and $-O$ ). About 




FIG. 3. Pulsed-field gel electrophoresis of intact DNA of VPX (lane 1), RCN (lane 2), CPV Brighton strain (lane 3), and VAC New York Board of Health, Wyeth strain (lane 4). Genome DNA sizes (shown in $\mathrm{kbp}$ ) estimated using phage Lambda DNA ladder markers were essentially the same as sizes estimated by summing of individual Hindlll fragment sizes.

$3 \mathrm{kbp}$ of RCN and VAC DNA account for a conserved domain at the DNA terminals (RCN HindllI-P and $-W$ comigrated and annealed with VAC Hind!II-K and $-\mathrm{N}$ ).

We noted, after renaturing formamide-denatured Hindlll cleavage products, that VPX fragments Hindlll$B(22.2 \mathrm{kbp})$ and $-H(10.4 \mathrm{kbp})$ were hairpin-end snapback fragments, as were DNA fragments HindIII-H and -O of RCN and fragments Hindlll-B and -G of VAC Lister strain (data not shown). When segments that span the WR VAC terminal fragments (Merchlinsky and Moss, 1988) HindlII-B (29 kbp) and Hindlli-C (25 kbp) were separately annealed with VPX HindllI-cleaved DNA, we estimated from autoradiograph hybridization signals (Table 2A) that the base sequence homology of the left- and right-end regions of VPX and WR VAC DNA was high. However, an inverted terminal repeat (ITR) cloned EcoRI segment of WR VAC (pE7-1) annealed with the VPX right-end fragment HindIII-H, producing a markedly stronger radiograph signal than against the VPX left-end fragment HindIII-B, suggesting that there was greater homology between the VAC and VPX DNA right-ends than the respective left-ends.

More specific information on the extent of the homology at the extreme ends of VPX and RCN DNAs was gained by cross-hybridizing with cloned TRS fragments. A WR VAC 70-bp Hinfl repeat fragment (from pAG-5) did not anneal with VPX DNA terminal fragments HindlII-B and $-\mathrm{H}$ or with RCN HindIII-H and -O; likewise, a 2.2-kbp Sall terminal of RCN (p1067) did not anneal with VPX or VAC DNAs (not shown), although VPX HindllI-H annealed at $65^{\circ}$ with RCN HindIII-H and -O (Table 2B). As shown in Table 2C, the VPX DNA left-end fragment HindlII-B $(22.2 \mathrm{kbp})$ annealed with both the RCN left-end Hindlll-O (4.9 kbp) and the adjacent RCN HindllI-D (15.8 kbp) fragments, and with both the RCN right-end Hindlll-H ( $8.9 \mathrm{kbp})$ and the adjacent RCN HindIII-K (7.4 kbp) fragments. Taken together, the resulls suggested that portions of the ITR of RCN, VPX, and VAC DNAs contain very similar sequences, but the TRSs are rather different in sequence (as mentioned in the introduction VAC and RCNTRS are structurally similar).

\section{Loci of specific-encoding DNA}

To further examine the extent of VPX and RCN genetic divergence, based on the biologic features, we reasoned that DNA-encoding proteins associated with ATls, cell fusion, small plaques, and nonhemorrhagic pocks might likely be detectable. Accordingly, Southern blots of Hindlll digests of VPX, RCN, CPV, and VAC DNAs (Fig. 5A) showed that DNA for the CPV ATI major protein (Fig. 5B) annealed at $65^{\circ}$ with VPX Hindill-C, RCN HindlII-L, CPV HindIII-A, and NYBH VAC HindIIIA. Further, DNA for the WR VAC 14-kDa fusion protein (Fig. 5C) annealed at $65^{\circ}$ with VPX Hindlll-E, RCN HindIII-F and -L, CPV HindIII-A, and NYBH VAC HindIII$A$ and DNA for the CPV 38-kDa serpin (Fig. 5D) annealed at $65^{\circ}$ with VPX Hindlll-A, RCN Hindlll-C, CPV HindlII-B, and Hindlll-B of NYBH VAC. Contrasting these strong DNA homologies, Fig. 5E shows that the PCR DNA homologous to the WR VAC VGF gene did not anneal at $65^{\circ}$ to RCN or VPX DNAs, but did anneal to CPV HindIII-D and NYBH VAC HindIII-B and -C. Hybridizations at $42^{\circ}$ gave an extremely faint autoradiograph signal (data not shown) which suggested that VPX HindIII-M and RCN HindllI-M might contain a cognate VGF DNA. Similarly, as shown in Fig. 5F, PCR DNA for bases +92 to +379 of the VAC N2L ORF that annealed at $65^{\circ}$ with VAC HindIII-N and CPV HindlII-C did not anneal with RCN or VPX DNAs; however, a faint signal was seen after annealing at $42^{\circ}$ (data not

TABLE 1

Volepox VIRUs DNA HindIII Fragment Sizes In Killobase PaIRS

\begin{tabular}{cccc}
\hline Fragment & Size & Fragment & Size \\
\hline A & 35.7 & $\mathrm{~L}$ & 6.0 \\
$\mathrm{~B}^{a}$ & 22.2 & $\mathrm{M}$ & 5.5 \\
$\mathrm{C}$ & 18.7 & $\mathrm{~N}$ & 5.0 \\
$\mathrm{D}$ & 14.7 & $\mathrm{O}$ & 4.4 \\
$\mathrm{E}^{b}$ & 13.5 & $\mathrm{P}$ & 3.4 \\
$\mathrm{~F}$ & 11.6 & $\mathrm{Q}$ & 3.0 \\
$\mathrm{G}$ & 11.0 & $\mathrm{R}$ & 2.6 \\
$H^{a, b}$ & 10.4 & $\mathrm{~S}$ & 2.5 \\
$\mathrm{I}$ & 8.0 & $\mathrm{~T}$ & 2.4 \\
$\mathrm{~J}$ & 7.7 & $\mathrm{U}$ & 1.9 \\
$\mathrm{~K}$ & 7.5 & $\mathrm{~V}$ & 1.2
\end{tabular}

Total DNA size: $222.8 \mathrm{kbp}$

\footnotetext{
DNA terminal fragment.

${ }^{b}$ HindllI-E 3-molar, HindllI-H 2-molar.
} 
TABLE 2A

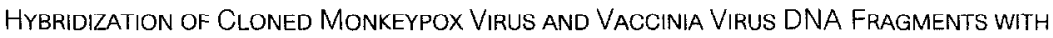
VOLEPOX VIRUS HindIII DNA FRAGMENTS BLOTTED TO NITROCELLULOSE ${ }^{a}$

\begin{tabular}{|c|c|c|c|c|c|c|c|c|c|c|c|c|c|c|c|c|c|c|c|c|c|c|}
\hline VPX Hindlll: & A & B & $\mathrm{C}$ & D & $E$ & $\mathrm{~F}$ & $\mathrm{G}$ & $\mathrm{H}$ & 1 & 」 & K & $\mathrm{L}$ & M & $\mathrm{N}$ & 0 & P & Q & $\mathrm{R}$ & $s$ & $\mathrm{~T}$ & $\mathrm{u}$ & $\mathrm{v}$ \\
\hline \multicolumn{23}{|l|}{ MPV } \\
\hline Hindlll-A & & & + & & + & + & & & & & & & & & & + & + & & & & & \\
\hline HindlII-B & + & & & & & & & & & & & & & & & & & & & & & \\
\hline \multicolumn{23}{|l|}{ VAC } \\
\hline HindllI-B subclones ${ }^{b}$ & & & & & & & & & & & & & & & & & & & & & & \\
\hline $\mathrm{pHd} / \mathrm{Sal}-\mathrm{B}$ & + & & & & & & & & & & & & & & & & & & & & & \\
\hline pSall-1 & + & & & & & & & & & & & & & & & & & & & & & \\
\hline $\mathrm{pSall-N}$ & & & & & & & & + & & & & & & & & & & & \pm & & & \\
\hline Hindlll-C subclones ${ }^{b}$ & & & & & & & & & & & & & & & & & & & & & & \\
\hline $\mathrm{pH} \mathrm{d} / \mathrm{Sal}-\mathrm{c}$ & & & & & & & + & & & & & & & & & & & & & & & \\
\hline $\mathrm{p}$ Sall-K & & & & & & & + & & & & & & & & & & & & \pm & & & \\
\hline $\mathrm{pE} 7-1$ & & \pm & & & & & & + & & & & & & & & & & & & & & \\
\hline HindllI-D & & & & & & & & & + & & & & & & & + & & + & & & & \\
\hline HindllI-[ & & & & & + & & & & & & & & & & & & & & & & + & \\
\hline HindllI-F & & & & + & & & & & & & & + & & & & & & & & & & + \\
\hline Hindlll-G & & & & & & & & + & & & & & & & & & & & & + & & \\
\hline Hindllli-H & & & & & & & & & & & + & & & + & & & & & & & & \\
\hline HindIII-I & & & & & & & & & & + & & & & & & & & & & & & \\
\hline Hindlll-J & & & & & & & & & & & & & & + & & & & & & & & \\
\hline HinndIII-K & & & & + & & & & & & & & & & & & & & & & & & \\
\hline HindllI-L & & & & & & & & + & & & & & & & & & & & & & & \\
\hline Hindlili-M & & & & + & & & & & & & & & & & & & & & & & & \\
\hline Hindlll-N & & & & + & & & & & & & & & & & & & & & & & & \\
\hline HindIII-O & & & & & & & & & & + & & & & & & & & & & & & \\
\hline
\end{tabular}

${ }^{a}$ Relative intensity of autoradiograph signais were scored strong $(+)$ or moderate $( \pm)$.

${ }^{b}$ Subcloned segments of the ITR region in WR VAC HindlII-B and -C fragments (Merchlinsky and Moss, 1988).

shown) which suggested that VPX Hindill-D and RCN HindllI-W might contain a cognate N2L DNA.

\section{Western blot analyses}

Having detected counterparts in the genome of VPX and RCN of genes encoding the CPV ATI 160-kDa major protein and the VAC $14-\mathrm{kD}$ a fusion protein, we next examined whether antisera would react with the analogues that we presumed were produced by VPX and RCN. Thus, Figs. 6 and 7, respectively, show the reactivities of specific sera against the CPV ATI protein and

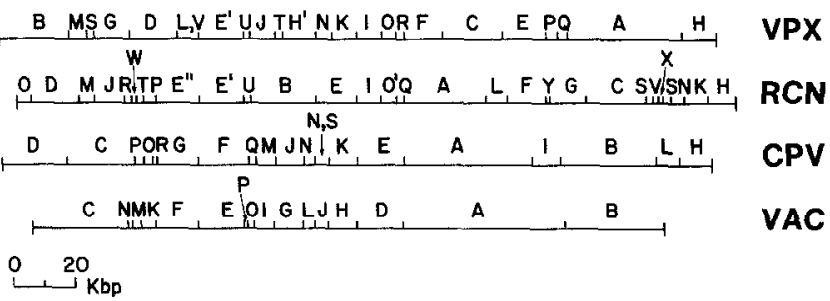

Fig. 4. Hindlll restriction maps for the DNA of volepox virus, raccoon poxvirus, Brighton cowpox virus, and the Wyeth NYBH strain of vaccinia virus. the WR VAC fusion protein with lysates of cells infected with VPX, RCN, CPV, or NYBH VAC. Compared with the expected CPV 160-kDa protein and the NYBH VAC ATI 94-kDa analogue, Fig. 6 shows a 150-kDa ATI analogue in the lysate of cells infected with VPX and a $155-\mathrm{kDa}$ protein in cells infected with RCN. In Fig. 6 , lane 3, minor CPV proteins of $<160 \mathrm{kDa}$ were seen that reacted with the ATI antiserum; these putative subspecies have also been seen by Patel et al. (1986), but their origin is unresolved. As shown in Fig. 7, MAb-C3 reacted with proteins in lysates of cells infected with RCN, VPX, CPV, or NYBH VAC and with a RCN virion protein. Based on migration of molecular weight markers, an analogue of $20 \mathrm{kDa}$ was found in VPX-infected cells and an $18-\mathrm{kDa}$ protein was detected in both the RCN-infected cells and RCN-purified virions. A $15-\mathrm{kDa}$ was the smallest size protein in CPV-infected cell lysates, and unlike WR VAC, our stocks of NYBH VAC showed a 15.7-kDa fusion protein. Curiously, lysates of cells infected with CPV or NYBH VAC also showed other proteins in the 14- to 19-kDa size range that bound to MAb-C3; we currently surmise that these are similar to variants of the fusion protein that arise in FEL cells infected WR VAC (Dallo et al., 1987). 


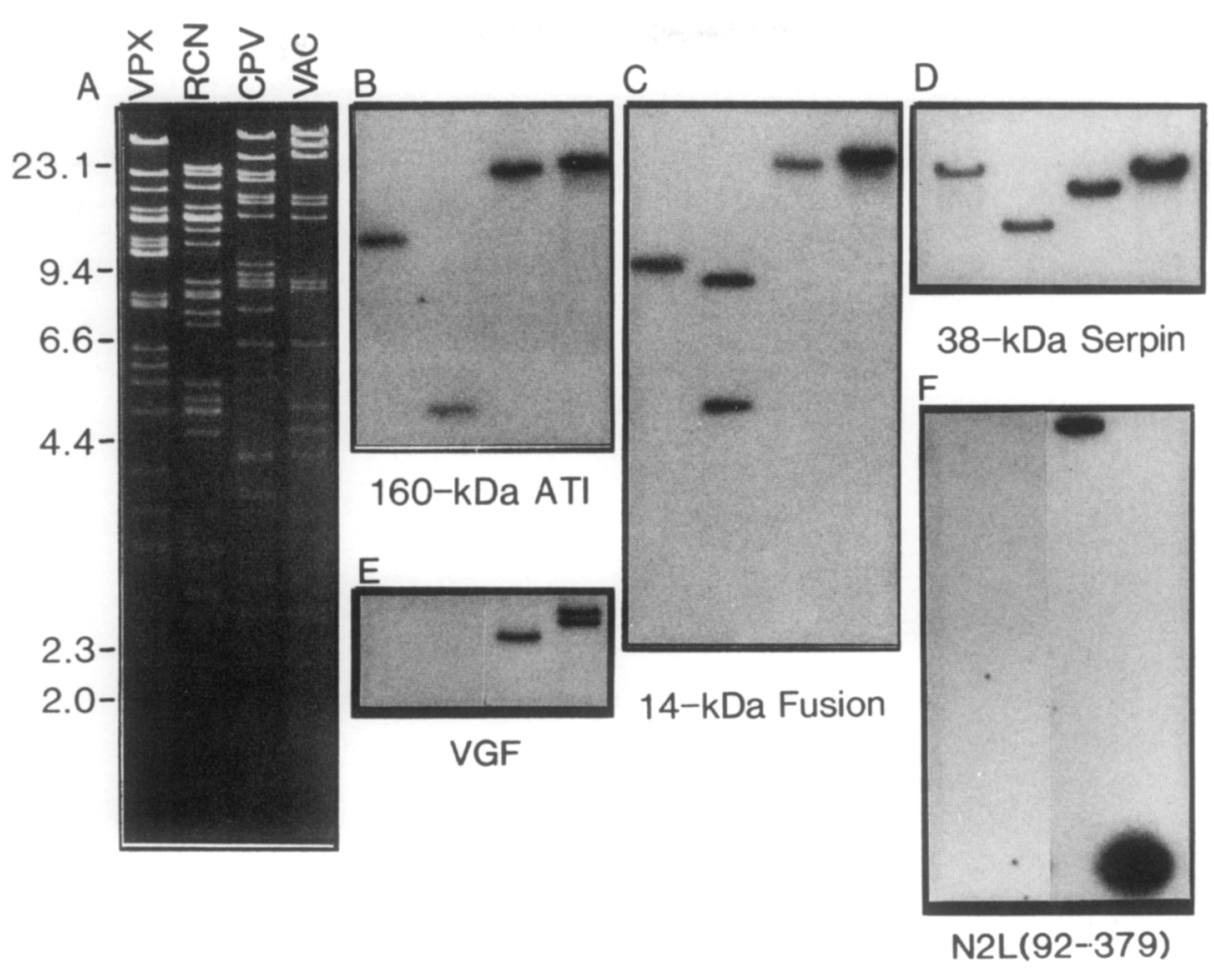

FIG. 5. Southern blot hybridization of HindllI digests (A) of the DNA of VPX, RCN, Brighton CPV, and NYBH VAC with cloned DNA fragments for the CPV 160-ATI protein (B), the VAC 14-kDa fusion protein (C), and the CPV 38-kDa serpin (D) and with segments amplified by PCR from DNA encoding the VAC VGF (E) and nucleotides 92-379 of the WR VAC ORF N2L (F). Lambda phage DNA Hindlll digest fragments were used as molecular weight markers.

\section{DISCUSSION}

Orthopoxviruses are closely related biologically and antigenically. Although DNAs of different orthopoxviruses cross-hybridize extensively, DNA restriction site mapping has been useful for differentiating species and variants. Previously, DNA maps (Mackett and Archard, 1979; Esposito and Knight, 1985) suggested that central region nucleotide sequences were highly conserved among orthopoxviruses and that terminal region DNA dissimilarities appear to be largely responsible for differences between species. In light of our present analysis of the VPX and RCN Hind II maps (Fig. 4) and detection at parallel loci in RCN and VPX DNA of analogues of five different components of $V A C$ and

\section{TABLE 2B}

HYBRIDIZATIONS OF ELECTROPHORETICALLY PURIFIED DNA FRAGMENTS OF VOLEPOX VIRUS WITH RACCOON POXVIRUS AND COWPOX VIRUS Hindill DNA Fragments on Nitrocellulose

\begin{tabular}{|c|c|c|c|c|c|c|c|c|c|c|c|c|c|}
\hline RCN Hindll: & $B$ & D & $E$ & $H$ & K & $M$ & 0 & CPV Hindlli: & $D$ & $\mathrm{H}$ & $J$ & $N$ & $S$ \\
\hline VPX Hindlll & & & & & & & & & & & & & \\
\hline HindIII-B & & + & & + & \pm & & + & & \pm & \pm & & & \\
\hline HindllI-H & + & & \pm & + & & & + & & \pm & \pm & + & + & \pm \\
\hline HindllI-M & & + & & & & + & & & & & & & \\
\hline
\end{tabular}

CPV (Fig. 5), it appears that considerable disparities in sequences can occur throughout the central and terminal regions of orthopoxvirus genomes, although the overall arrangement of genetic information is conserved. In this regard, we have also noted (Cavallaro and Esposito, 1992) that the HA protein sequences of VPX and RCN are moderately diverged from the highly similar HA protein sequences of many other orthopoxviruses.

In the present study, we noted that VPX- and RCNinfected cells contained classic, spherical $\mathrm{V}^{+} \mathrm{ATI}$ and RCN-infected cells also showed pleomorphic, virus-laden inclusions (Fig. 2) that resembled inclusions in CPV-infected cells artificially fused by coinfection with Sendai virus (Shida et al., 1977). It is unclear what role membrane alterations, like syncytia formation, play in the morphogenesis of ATIs. Inclusions, like spherules of entomopoxviruses, have long been thought to aid in the survival of poxviruses in environments with limited transmission opportunities (Dales and Pogo, 1981; Buller and Palumbo, 1991). Why the ATI major protein varies in size in cells infected with VPX, RCN, CPV, and VAC (Fig. 6) is unresolved, but a concept developed during similar analyses of ATI proteins of CPV, VAC, MPV, ECT, and RCN (data of Esposito, Patel, and Pickup cited in Patel and Pickup, 1987) suggested that 
TABLE 2C

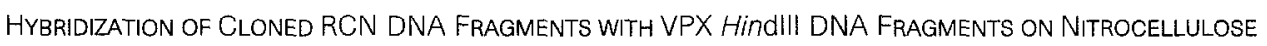

\begin{tabular}{|c|c|c|c|c|c|c|c|c|c|c|c|c|c|c|c|c|c|c|c|c|c|c|}
\hline VPX Hindlll: & A & B & C & D. & $E$ & $\mathrm{~F}$ & G & $H$ & 1 & J & K & L & M & N & 0 & $\mathrm{P}$ & $Q$ & $\mathrm{R}$ & $s$ & $\mathrm{~T}$ & U & V \\
\hline \multicolumn{23}{|l|}{$\mathrm{RCN}$} \\
\hline HindIII-E & & & & & & \pm & & & & & + & & & + & & & & & & & & \\
\hline HindIII-E' & & & & & + & & & & & & & & & & & & & & & & & \\
\hline $\begin{array}{l}\text { Hindlll-E"E } \\
\text { Hindlll-F }\end{array}$ & & & \pm & \pm & + & & & & & & & + & & & & & & & & & & + \\
\hline HindlII-G & t & & & & & & & & & & & & & & & + & + & & & & & \\
\hline Hindlll-I & & & & & & & & & + & & & & & & & & & & & & & \\
\hline Hindlll-K & + & + & & & & & & & & & & & & & & & & & & & & \\
\hline Hindlll-M & & & & & & & & & & & & & + & & & & & & + & & & \\
\hline Hindlll-N & + & & & & & & & & & & & & & & & & & & & & & \\
\hline Hindlll-O' & & & & & & & & & & & & & & & + & & & & & & & \\
\hline HindllI-P & & & & + & & & & & & & & & & & & & & & & & & \\
\hline HindllI-Q & & & & & & & & & & & \pm & & & & & & & + & & & & \\
\hline Hindlli-S & + & & & & & & & & & & & & & & & & & & & & & \\
\hline Hindlll-T & & & & + & & & & & & & & & & & & & & & & & & \\
\hline HindllI-U & & & & & & & & & & & & & & & & & & & & & + & \\
\hline HindlIIVV & + & & & & & & & & & & & & & & & & & & & & & \\
\hline Hindlll-W & & & & + & & & & & & & & & & & & & & & & & & \\
\hline Hindll1-X & + & & & & & & & & & & & & & & & & & & & & & \\
\hline Hindlll-Y & & & & & & & & & & & & & & & & + & & & & & & \\
\hline $\mathrm{p} 1067^{\circ}$ & & \pm & & & & & & \pm & & & & & & & & & & & & & & \\
\hline
\end{tabular}

${ }^{a}$ RCN Sall 2.2-kbp end fragment (Parsons and Pickup, 1987).

the different-sized ATI proteins of different orthopoxviruses might reflect virus adaption to various hosts and econiches.

Curiously, VPX and RCN induce syncytia (Fig. 1) despite the fact that they are $\mathrm{HA}^{+}$(Thomas et al., 1975; Regnery, 1987). The nature of the interactions of viral and cell proteins involved in syncytia formation are unclear; however, the VAC 14-kDa fusion protein has been implicated as a major component of the process since fusion can be induced by $\mathrm{pH} 5$ treatment of VACinfected cells (Rodriguez and Esteban, 1987; Rodri-

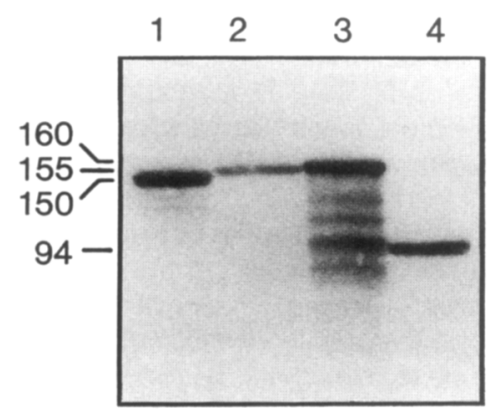

FIG. 6. Western blot analysis of the reactivities of affinity-purified hyperimmune rabbit serum against $\mathrm{V}^{-}$ATIs of CPV and lysates of VERO cells infected with VPX (lane 1), RCN (lane 2), Brighton CPV (lane 3), and NYBH VAC (lane 4). Proteins in the lysates were dena tured and then separated by SDS-PAGE in a $12 \%$ gel. The gel was blotted, reacted with antiserum, and the reaction products were detected with $\left[{ }^{125} 1\right]$ protein-A as described in the text. guez et al., 1987). Recently, the VAC HA protein (Seki et al., 1990) and the serpin-like gene product of the VAC ORF K2L (R. Moyer, personal communication) have been shown to be inhibitors of cell fusion, since fusion ensues when these genes are interrupted or specifically altered. The basis of syncytia formation by RCN and VPX is unresolved; however, current data (Cavallaro and Esposito, 1992) has suggested that the RCN HA protein is conformationally quite different from the VAC HA protein and that parts of the RCN and VPX

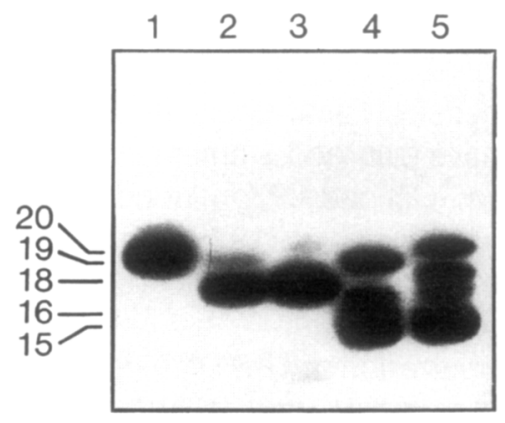

FIG. 7. Western blot analysis of monoclonal antibody MAb-C3 reactivity with lysates of VERO cells infected with VPX (lane 1), RCN (lane 2), Brighton CPV (lane 4), NYBH VAC (lane 5), or with sucrose-gradicnt purificd RCN virions (lane 3). Proteins were denatured and then separated by SDS-PAGE in 10-20\% polyacrylamide gradient gel. The gel was blotted, reacted with antiserum, and the reaction products were detected with $\left[{ }^{125} \mid\right]$ protein-A as described in the text. 
HA sequences are quite diverged from those in VAC. It may be that the different fusion protein (Fig. 7) and HA protein (Cavallaro and Esposito, 1992) or an aberration in the $\mathrm{K} 2 \mathrm{~L}$ analogue are responsible, together or independently, for the ability of VPX and RCN to induce syncytia.

It was of interest to note that VPX and RCN contained DNA related to CPV DNA encoding the $38-\mathrm{kDa}$ serpin homologue, especially since VPX and RCN produce nonhemorrhagic pocks (Fig. 1). It has been proposed that the CPV 38-kDa serpin homologue has anti-inflammatory properties on CPV-infected CAMs and that the lack of inflammatory cell activity aids CPV production of hemorrhagic pocks on the CAM. Additionally, interruption of the $38-\mathrm{kD}$ a gene correlated with decreased CPV virulence in mice (Palumbo et al., 1989; Chua et al., 1990; Palumbo and Buller, 1991; Buller and Palumbo, 1991). Although no antiserum was available to reveal whether the RCN or VPX produced an analogue of the 38-kDa protein, in another study, we insertionally interrupted the cognate serpin DNA in RCN and noted extensive inflammation of pocks on CAMs infected with the mutant, and the mutant did not induce flaccid leg paralysis, as does RCN (Thomas et al., 1975) when injected into neonatal mice (Tamin et al., manuscript in preparation).

In the present report, reduced stringency hybridizalions suggested that cognate genes for the VAC VGF and the $\alpha$-amanitin resistance protein may be present in left-end region of VPX and RCN DNA, although we found that these DNAs are highly conserved in many other mapped orthopoxviruses (data not shown). The consequence of the high degree of divergence of these genes in VPX and RCN is unclear. Both proteins seem generally to enhance the efficiency of virus replication. The VGF has been implicated in invoking cell proliferation around infectious centers, thereby increasing the number of virus-susceptible cells (Buller et al., 1988a,b) and $\alpha$-amanitin target protein has been implicated in involving VAC replication with host cell nuclear processes (Tamin et al., 1988, 1991). It may be that the putative diverged $\alpha$-amanitin target protein and VGF genes in RCN and VPX influence their replication. Relevantly, Thomas et al. (1975) reported that the ability of RCN to produce pocks decreases within a few viral passages on CAMs.

Cross-hybridization of TRS DNA was consistent with the concept that VPX and RCN have separately diverged genomes compared with other mapped orthopoxviruses. VAC TRS appear highly conserved among other orthopoxviruses (Esposito and Knight, 1985).

Taken together, the current data suggest that the topologic arrangement of information in the genome of RCN and VPX is similar to that of other mapped ortho- poxviruses, but there are a significant number of domains of central and terminal region sequences that are diverged from the other orthopoxviruses. It may be that orthopoxviruses not indigenous to the Americas have a mutual progenitor which is phylogenetically separated from the ancestor(s) of VPX and RCN, and that host adaption has effected separate evolution of the orthopoxviruses of the Americas from those of Eurasia and Africa.

\section{ACKNOWLEDGMENTS}

We thank Edwin George and Brian Holloway for oligonucleotides and Felicia Stamey for advice on PCR. Azaibi Tamin was awarded a National Research Council Associateship while on leave from the National University of Malaysia.

\section{REFERENCES}

Alexander, A. D. Flyger, V., Herman, Y. F., McConnell, S. J., ROTHSTEIN, N., and YAGER, R. H. (1972). Survey of wild mammals in a Chesapeake Bay area for selected zoonoses. J. Wild. Dis. 8 , 110-126.

BAROUDY, B. M., and Moss, B. (1982). Sequence homologous of diverse length tandem repetitions near ends of vaccinia virus genome suggest unequal crossing over. Nucleic Acids Res. 10, 5673-5679.

Buller, R. M., ChakrabartI, S., Cooper, J. A., Twardzik, D. R., and Moss, B. (1988a). Deletion of the vaccinia virus growth factor gene reduces virus virulence. J. Virol. 62, 866-874.

Buller, R. M., Chakrabarti, S., Moss, B., and Fredrickson, T. (1988b). Cell proliferative response to vaccinia virus is mediated by VGF. Virology 164, 182-192.

Buller, R. M., and Palumbo, G. J. (1991). Poxvirus pathogenesis. Microbiol. Rev. 55, 80-122.

BURNETTE, W. N. (1981). Western blotting: Electrophoretic transfer of proteins from sodium dodecylsulfate-polyacrylamide gels to unmodified nitrocellulose and radiographic detection with antibody and radioiodinated protein A. Anal. Biochem. 112, 195-203.

CAVAllaro, K., and Esposito, J. J. (1992). Sequences of the raccoon poxvirus hemagglutinin protein. Virology 189 ,.

CHu, G., VollRATH, D., and Davis, R. W. (1986). Separation of large DNA molecules by contour-clamped homogeneous fields. Science 234, 1582-1585.

Chu^, T. P., SMith, C. E., Reith, R. W., and Williamson, J. D. (1990). Inflammatory responses and the generation of chemoattractant activity in cowpox virus-infected tissues. Immunology 69, 202208.

DALES, S., and Pogo, B. T. (1981). The poxviruses. Virol. Monogr. 18, $1-109$.

Dallo, S., Rodriguez, J. F., and Esteban, M. (1987). A 14K envelope protein of vaccinia virus with an important role in virus -host cell interactions is altered during virus persistence and determines the plaque size phenotype of the virus. Virology 159, 423-432.

Esposito, J. J., Cabradilla, C. D., Nakano, J. H., and OBiJeski, J. F. (1981a). Intragenomic sequence transposition in monkeypox virus. Virology 109, 231-243.

EsPOSITO, J. J., CONDIT, R., and OBIJESKI, J. F. (1981b). The preparation of orthopoxvirus DNA. J. Virol. Methods 2, 175-179.

EsPosiTo, J. J., and KNIGHT, J. C. (1985). Orthopoxvirus DNA: A comparison of restriction profiles and maps. Virology 143, 230-251. 
Esposito, J. J., Knight, J. C., Shaddock, J. H., Novembre, F. J., and BAER, G. M. (1988). Successful oral rabies vaccination of raccoons with raccoon poxvirus recombinant expressing the rabies virus glycoprotein. Virology 165, 313-316.

FENNER, F., WITTEK, R., and DUMBEIL, K. R. (1989). "The Orthopoxviruses." Academic Press, New York.

FUNAHASHI, S., SATO, T., and SHIDA, H. (1988). Cloning and characterization of the gene encoding the major protein of the A-type inclusion body of cowpox virus. J. Gen. Virol. 69, 35-47.

GONG, S. C., LAI, C. F., and ESTEBAN, M. (1990). Vaccinia virus induces cell fusion at acid $\mathrm{pH}$ and this activity is mediated by the $\mathrm{N}$-terminus of the $14-\mathrm{kDa}$ virus envelope protein. Virology 178 , $81-91$.

HERMAN, Y. F. (1964). Isolation and characterization of a naturally occurring poxvirus of raccoons. Bacteriol. Proc. 64th Annual Meeting, American Society of Microbiologists, p. 117.

JoHnson, D. A., GAUTSCH, J. W., SPORTMAN, J. R., and ELDER, J. H. (1984). Improved technique utilizing nonfat dry milk for analysis of proteins and nucleic acids transferred to nitrocellulose. Gene Anal. Tech. 1, 3-8.

KNiGht, J. C., Novembre, F. J., Brown, D. R., Goldsmith, C. S., and Esposito, J. J. (1989). Studies on Tanapox virus. Virology 172 , $116-124$.

LAEMMLI, U. K. (1970). Cleavage of structural proteins during the assembly of the head of bacteriophage T4. Nature (London) 227 , 680-684.

MACKETT, M., and ARCHARD, L. C. (1979). Conservation and variation in ur thopoxvirus genome structure. J. Gen. Virol. 45, 683-701.

MERCHLINSKY, M., and Moss, B. (1988). Sequence-independent replication and sequence-specific resolution of plasmids containing the vaccinia virus concatemer junction: Requirements for early and late trans-acting factors. Cancer Cells 6, 87-93.

PALUMBO, G. J., and BULLER, R. M. (1991). Inhibitors of the lipoxygenase pathway specifically block orthopoxvirus replication. Virology 180, 457-463.

PALUMBO, G. J., PICKUP, D. J., FREDRICKSON, I. N., MCINTYRE, L. J., and BULLER, R. M. (1989). Inhibition of an inflammatory response is mediated by a $38-k D$ a protein of cowpox virus. Virology 172,262 273

PARSons, B. L., and PICKup, D. J. (1987). Tandemly repeated sequences are present at the ends of the DNA of raccoon poxvirus. Virology 161, 45-53.

PARSONS, B. L., and PICKUP, D. J. (1990). Transcription of orthopoxvirus telomers at late times during infection. Virology 175, 69-80.

PATEL, D., and PICKUP, D. J. (1987). Messenger RNAs of a strongly expressed late gene of cowpox virus contain 5 -terminal poly(A) sequences. EMBO J. 6, 3787-3794.

PATEL, D., PICKUP, D. J., and JOKLIK, W. K. (1986). Isolation of cowpox virus A-type inclusions and characlerization of their major protein component. Virology 149, 174-189.
PICKUP, D. J., INK, B. S., HU, W., RAY, C. A., and JOKLIK, W. K. (1986), Hemorrhage in lesions caused by cowpox virus is induced by a viral protein that is related to plasma protein inhibitors of serine proteases. Proc. Natl. Acad. Sci. USA 83, 7698-7702.

REGNERY, D. C. (198/). Isolation and partial characterization of an orthopoxvirus from a California vole (Microtus californicus). Arch. Virol. 94, 159-162.

Rodriguez, J. F., and EstabAN, M. (1987). Mapping and nucleotide sequence of the vaccinia virus gene that encodes a 14-kilodalton fusion protein. J. Virol. 61, 3550-3554.

RODRIGUEZ, J. F., JANECZKO, R., and ESTABAN, M. (1985). Isolation and characterization of neutralizing monoclonal antibodies to vaccinia virus. J. Virol. 56, 482-488.

Rodriguez, J. F., PAEZ, E., and Estaban, M. (1987). A 14,000-Mr envelope protein of vaccinia virus is involved in cell fusion and forms covalently linked trimers. J. Virol. 61, 395-404.

SAMBROOK, J., FriTSCH, E. F., and MANIATIS, T. (1989). "Molecular Cloning: A Laboratory Manual." Cold Spring Harbor Laboratory, Cold Spring Harbor, NY.

SEKI, M., OIE, M., ICHIHASHI, Y., and SHIDA, H. (1990). Hemadsorption and fusion inhibition activities of hemagglutinin analyzed by vaccinia virus mutants. Virology 175, 372-384.

SHIDA, H., I ANABE, K., and MATSUMOTO, S. (1977). Mechanism of virus occlusion into A-type inclusion during poxvirus infection. $V /$ rology $76,217-233$

TAMIN, A., Esposito, J., and Hruby, D. (1991). A single nucleotide substitution in the $5^{\prime}$-untranslated region of the vaccinia N2L gene is responsible for both alpha-amanitin-resistant and temperaluresensitive phenotypes. Virology 182, 393-396.

Tamin, A., Villarreal, E. C., Weinrich, S. L., and Hruby, D. E. (1988). Nucleotide sequence and molecular genetic analysis of the vaccinia virus Hindill N/M region encoding the genes responsible for resistance to alpha-amanitin. Virology 165, 141-150.

Thomas, E. K., PALmer, E. L., OBIJeskl, J. F., and NAKano, J. H. (1975). Further characterization of raccoonpox virus. Arch. Virol. 49, 217227.

TOWBIN, H. R., and GORDON, J. (1984). Immunoblotting and dot immunobinding: Current status and outlook. J. Immunol. Methods $72,313-340$.

TowBin, H. T., StaElelin, T., and Gordon, J. (1979). Electrophoretic transfer of proteins from polyacrylamide gels to nitrocellulose: Procedure and some applications. Proc. Natl. Acad. Sci. USA 76, 4350-4354.

VenKATESAN, S., Gershowitz, A., and Moss, B. (1982). Complete nucleotide sequences of two adjacent early vaccinia virus genes located within the inverted terminal repetition. J. Virol. 44, 637646.

VOLLRATH, D., and DAVIS, R. W. (1987). Resolution of DNA molecules greater than 5 megabases by contour-clamped homogeneous electric fields. Nucleic Acids Res. 15, 7865-7876. 